IN THE Red Cross WorLd

\title{
What role can the Algerian Red Crescent play in the anti-tuberculosis campaign?
}

The International Review takes pleasure in publishing the following article by Dr. D. Larbaoui, former president of the Algerian Red Crescent and at present a doctor at the C.H.U. in Algiers. He gives some personal opinions on a particularly important subject.

National Red Cross Societies have taken part in anti-tuberculosis campaigns for the last 50 years or more. As early as 1907, the VIIIth International Conference of the Red Cross expressed the wish that "Societies would participate in the peace-time struggle against tuberculosis".

Since then, a series of resolutions by the highest bodies of the League of Red Cross and Red Crescent Societies have been followed up by the concrete results achieved by some National Societies and also by more effective co-operation with the International Union against Tuberculosis.

One outstanding example which illustrates this valuable action by the Red Cross is the work undertaken after the Second World War by the Danish, Swedish and Norwegian Red Cross Societirs. The wide-scale international campaign against tuberculosis they began in European countries ravaged by war, was soon backed up by the International Children's Emergency Fund, and was extended to various countries in Africa and Asia. The campaign was brought to a close in 1961 .

The results of this large-scale preventive work of which 23 countries benefited, were that 40 million people were tested for tuberculosis and 17 million were immunized against tuberculosis by BCG inoculation.

This extensive activity further increased humanity's debt to the Red Cross.

The campaign was carried out in Algeria in 1950 and 1951. 2,500,000 people were tested and over one million inoculated. 


\section{IN THE Red Cross Wored}

\section{What is the Algerian Red Crescent?}

Like all the 108 National Red Cross, Red Crescent and Red Lion and Sun Societies in the world, the Algerian Red Crescent is an independent national voluntary association, auxiliary to the public authorities. It was recognized officially as such hardly four years ago by the Algerian Government, and by the ICRC and the League.

"Its broad objective is to prevent and alleviate suffering with complete impartiality, disregarding any distinction of race, nationality, class, creed or political opinion.

In time of war it functions as an auxiliary service of the army medical corps in every sphere covered by the Geneva Conventions to which Algeria is a signatory.

Among the functions which devolve on it in time of peace are those which contribute to the prevention and cure of epidemics and sickness and the improvement of health standards, particularly by the spread of knowledge of hygiene".

These phrases from the Algerian Red Crescent statutes show clearly that in time of peace it is a statutory obligation for the Red Crescent to act as an auxiliary to the public health services in the prevention of sickness and the improvement of health.

\section{What principles should guide its action?}

In our view there are three principles in particular which should be taken by the Algerian Red Crescent as guidelines for its participation in the struggle against tuberculosis.

1. Auxiliary status. - The A.R.C. is an auxiliary service to the public health authorities in peace-time and as such cannot and should not act except to help in the implementation of a programme drawn up by the health authorities; nor should it exceed the scope of such a programme. Naturally the authorities must undertake the essential central co-ordination to make all efforts effective.

2. The reinforcement function. - Red Cross and Red Crescent Society action should not overlap that of the authorities or of 
other voluntary associations. The A.R.C.'s function is complementary; it should make up for omissions which the health authorities are unable to avoid. This does not imply that the Red Crescent may take no initiative of its own. It may do this provided it obtains the agreement and support of the health authorities and that its action is properly geared to fit in with the programme to combat tuberculosis.

3. Vicarious function. - To stand in the breach is another, though temporary, duty a National Society performs whenever a serious shortcoming is revealed in the struggle against tuberculosis.

\section{What can its action be?}

The Algerian Red Crescent has existed for only four years, and has only just come to the end of a long and difficult period in which it has been organizing and building up. By comparison with the many tasks it has set itself, its resources are quite insignificant. Consequently, it must be admitted that the rôle of the Algerian Red Crescent in the campaign against tuberculosis can for the present only be on a modest scale, even though the faith and enthusiasm of its leaders and members contributes in no small measure to offsetting the material difficulties with which it has to contend.

Its perforce restricted action can however be brought into play in mass information and education, which are interrelated.

Thanks to the prestige it has already acquired and the potential of its voluntary members, the Algerian Red Crescent can and should exert a beneficial influence on public awareness of the problems involved, by

- making known the disastrous physical and moral effects which sickness insidiously causes to individuals, the family and the nation;

- enlightening the public on contagion and the danger from undisciplined or unco-operative patients;

- teaching elementary principles and practice of personal and collective hygiene;

- spreading knowledge on prevention as well as on the benefits and demands of treatment; 


\section{IN THE RED CROSS WORLD}

- refuting those who belittle the benefits of treatment and preventive action.

To awaken the population to the danger which threatens it is within the scope of the Algerian Red Crescent, despite the scant resources available to it.

Its voluntary workers must show themselves to have initiative, imagination, an original approach and, especially, determination. These are the attributes which, in 1864, enabled Henry Dunant to have the First Geneva Convention accepted, only five years after the slaughter of Solferino which he witnessed on June 24, 1859.

These same qualities are displayed daily by 108 National Red Cross Societies throughout the world.

There is no doubt that co-operation from the public can be obtained by the education and mass communication which the population is entitled to demand.

Mass information and education involves full commitment; so does the Algerian Red Crescent Society's contribution to the campaign against tuberculosis. With all the resources at its command, the Society must promote prevention, treatment, material and psychological welfare of individual patients, care of patients' children, hygiene in their homes and habits, and rehabilitation after cure.

This list could be increased to include all the individual and collective actions which occur to the inventive imagination of Red Crescent volunteers.

The result of their efforts to inform and educate, when properly organized and co-ordinated, with a definite aim in view, can and should be a worthwhile contribution to early diagnosis, better preventive measures, and better treatment.

Sustained efforts to achieve early diagnosis, prevention and better treatment, are the first steps towards checking and finally eradicating tuberculosis.

Dr. D. LARBAOUI 